\title{
Değişken kesitli Timoshenko kolonlarının tamamlayıcı fonksiyonlar yöntemiyle burkulma analizi
}

\author{
Buckling analysis of Timoshenko columns having variable cross-section by \\ complementary functions method
}

\author{
Burkay Sivri, *1 (D), Beytullah Temel ${ }^{1 \text { (it) }}$ \\ ${ }^{1}$ Çukurova Üniversitesi, İnşaat Mühendisliği Bölümü, 01330, Adana Türkiye
}

\begin{abstract}
Özet
$\mathrm{Bu}$ çalışmada, eksenel yük altında değişken kesitli kolonların burkulması Tamamlayıcı Fonksiyonlar Yöntemi (TFY) ile incelenmiştir. Eleman boyunca kesit özellikleri sürekli değişen kolonlar Timoshenko kiriş teorisine göre modellenmiştir. İç kuvvet-şekil değiştirme ilişkileri ve denge denklemleri kullanılarak burkulma davranışını idare eden birinci mertebeden adi diferansiyel denklem takımı elde edilmiştir. Farklı sınır koşulları için eleman boyunca farklı koniklik değerlerinin ve uzunluk/kalınlık oranlarının burkulma yükü üzerindeki etkileri araştırılmıştır. Hesaplanan boyutsuz burkulma yükleri literatürdeki mevcut değerler ve Abaqus sonlu elemanlar programından elde edilen sonuçlar ile test edilmiştir. TFY'nin değişken kesitli kolonların elastik burkulma problemine uygulanabilirliği gösterilmiştir.
\end{abstract}

Anahtar kelimeler: Burkulma analizi, Tamamlayıc1 fonksiyonlar yöntemi, Timoshenko kolonu

\section{Giriș}

Taşıyıcı sistemlerde kullanılan kolon elemanlar, çubuk ekseni doğrultusunda basınç kuvveti etkisi altındadır. $\mathrm{Bu}$ etkiden dolayı burkulma davranışlarının bilinmesi tasarım için önemlidir. Havacılık, uzay, tıp, makina ve inşaat mühendisliği gibi alanlarda üniform kesitler ve homojenizotrop malzeme özellikleri istenilen mekanik özellikleri sağlamayabilir. Mimari ve optimum mühendislik tasarımı için yapı elemanı boyunca değişken kesit ve malzeme özellikleri kullanılmaktadır. Gelişen eleman üretim teknikleriyle birlikte yap1 elemanları bu talepleri karşılayabilecek şekilde imal edilebilir. Malzeme ve kesit özelliklerinin eleman ekseni ve/veya kesiti boyunca sürekli olarak değiştiği yapı elemanlarının mekanik davranışlarının bilinmesi bu sebepten gereklidir. Bu elemanların burkulma, serbest titreşim, zorlanmış titreşim, yorulma, aşınma, tokluk gibi mekanik özelliklerinin araştııılması önem kazanmıştır. Li [1], uygulamada sıklıkla karşılaşılan durumlar için değişsen kesitli kolonların burkulma analizlerinde Bessel denklemlerini kullanmıştır. Elishakoff [2], homojen-izotrop olmayan kolonların burkulma yükünü, polinom tipi malzeme fonksiyonları için bulmuştur. Lee ve Lee [3], malzeme ve

\begin{abstract}
In this study, the buckling of variable cross-section columns under axial load is investigated by the Complementary Functions Method (CFM). Columns whose cross-sectional properties change continuously throughout the element are modeled according to the Timoshenko beam theory. By using the internal force-strain relations and equilibrium equations, a set of first-order ordinary differential equations governing the buckling behavior is obtained. The effects of different taper values and length/thickness ratios on the buckling load along the element are investigated for different boundary conditions. The calculated dimensionless buckling loads are tested with the available values in the literature and the results obtained from the Abaqus finite element program. The applicability of the CFM to the elastic buckling problem of variable cross-section columns has been demonstrated.
\end{abstract}

Keywords: Buckling analysis, Complementary functions method, Timoshenko column

kesit özelliklerinin kolon ekseni boyunca doğrusal değiştiği Euler-Bernoulli kolonlarının serbest titreşim ve burkulma analizini integral metodu ile çözmüşlerdir. Coşkun ve Atay [4], üniform ve değişken kesitli Euler-Bernoulli teorisine dayanan kolonların burkulmasını varyasyonel iterasyon yöntemiyle bulmuşlardır. Shahbaa ve arkadaşları [5], eksenel yönde fonksiyonel derecelenmiş kirişlerin stabilite ve serbest titreşim analizini sonlu eleman metodu kullanarak yapmışlardır. Analizler için kullanılan kiriş eleman modelini, şekil fonksiyonları kullanarak elde etmişlerdir. Gören ve Erim [6], on farklı kademeli ve kademesiz kirişin kritik burkulma yüklerini sonlu eleman ve sonlu elemantransfer matris metotlarını kullanalarak hesaplamışlardır. Huang ve Li [7], üniform olmayan ve eksen boyunca eğilme rijitliği değişen Euler-Bernoulli kolonlarının burkulma davranışlarını idare eden diferansiyel denklemi, Fredholm integraline indirgemişlerdir. Soltani [8], elastik zemine oturan eksenel yönde derecelenmiş Timoshenko kolonlarının burkulma analizini sonlu eleman modeli kullanarak gerçekleştirmiştir. Rajasekaran [9], malzeme ve kesit özelliklerinin fonksiyonel olarak değiştiği kolonların titreşim ve burkulmasını diferansiyel transformasyon yöntemiyle araştırmıştır. Shahba ve arkadaşları [10], elastik

\footnotetext{
* Sorumlu yazar / Corresponding author, e-posta / e-mail: bsivri@cu.edu.tr (B. Sivri)

Geliş / Recieved:13.09.2021 Kabul / Accepted: 11.10.2021 Yayımlanma / Published: 14.01.2022

doi: 10.28948/ngmuh.994891
} 
mesnetli eksenel yönde derecelenmiş Timoshenko teorisine dayalı kolonların serbest titreşim ve stabilite analizlerini sonlu elemanlar analiziyle incelemişlerdir. Soltani ve Asgarian [11], eksenel yönde fonksiyonel derecelenmiş Timoshenko kolonlarının sonlu elemanlar formülasyonu ile lineer stabilite analizini gerçekleştirmiş̧lerdir. Akgöz [12], değişken kesitli kolonların burkulma yükünü Ritz yöntemiyle bulmuştur. Kiriş modellerinde klasik kiriş teorisi kullanılmış olup, sınır koşullarının ve koniklik oranının burkulma yüküne etkisini parametrik olarak incelemiştir.

$\mathrm{Bu}$ çalışmada Timoshenko teorisine dayalı modellenen ekseni boyunca değişken kesitli kolonların burkulma analizi TFY ile gerçekleştirilmiştir. TFY kullanmanın temel amacı sınır değer problemini başlangıç değer problemine dönüştürmektir. Yöntem sayesinde bilinmeyen fonksiyonların tamamı bir kerede elde edilebilir. Diferansiyel denklem çözümünde kullanılan Shooting Metodu başlangıç koşullarını belirlemek için deneme yanılma yöntemini kullanırken, TFY bağımsız başlangıç koşulları kullanarak daha az matematiksel işleme ihtiyaç duyar. Bu sayede farklı kesit değişim fonksiyonlarına sahip kolonların analizleri daha kısa sürede yapılabilir. Yazarların bilgisine göre, literatürde değişken kesitli Timoshenko kolonlarının burkulma yüklerinin TFY ile çözümüne rastlanmamıştır. Analizler, Python dilinde hazırlanan program aracılığıyla çözülmüştür. Çözümlerde homojenizotrop malzeme kullanılmıştır. Bu çalışmada elde edilen burkulma yükleri, literatürdeki mevcut sonuçlar ve sonlu eleman programından bulunan sonuçlar ile karşılaştırılmıştır. Farklı sınır koşulları için koniklik değerlerinin ve uzunluk/kalınlık oranlarının burkulma yüküne etkisi parametrik olarak incelenmiştir.

\section{Materyal ve metot}

Burkulma davranışını idare eden kanonik denklemler, iç kuvvet-şekil değiştirme ilişkisinden ve serbest cisim diyagramı üzerinden yazılan denge denklemlerinden elde edilecektir.

Timoshenko teorisine göre eksenel yer değiştirme $U_{x}$ ile düşey yer değiştirme $U_{z}$ Denklem (1)'deki gibi ifade edilebilir. Eksenel birim şekil değiştirme $\varepsilon_{x}$ ve açısal birim şekil değiştirme $\gamma_{x z}$ ifadeleri Denklem (2-3)'deki gibi yazılır [13].

$$
\begin{gathered}
U_{x}=u(x)+z \theta(x) \quad, \quad U_{z}=w(x) \\
\varepsilon_{x}=\frac{\partial U_{x}}{\partial x}=u^{\prime}+z \theta^{\prime} \\
\gamma_{x z}=\theta+w^{\prime}
\end{gathered}
$$

Eksenel $\mathrm{P}$ basınç kuvveti taşıyan dikdörtgen kesitli kolonlarda; $N$ normal kuvveti, $M$ eğilme momenti, $Q$ kesme kuvveti olmak üzere iç kuvvet-şekil değiştirme ilişkileri Denklem (4-6) 'da verilmektedir.

$$
\begin{gathered}
N=P \\
M=E I(x) \theta^{\prime}
\end{gathered}
$$

$$
Q=k_{s} A(x) G\left(\theta+w^{\prime}\right)
$$

Burada, E elastisite modülünü, G kayma modülünü, $k_{s}$ kesite bağlı kayma düzeltme katsayısını, $v$ poisson oranını, $\theta$ dönmeyi, $w$ düşey yer değiştirmeyi göstermektedir.

Eksenel P kuvveti altındaki kolonun serbest cisim diyagramı Şekil 1. üzerinden b noktasına göre toplam moment dengesi yazılırsa, moment değişimi Denklem (7)'deki gibi bulunabilir.

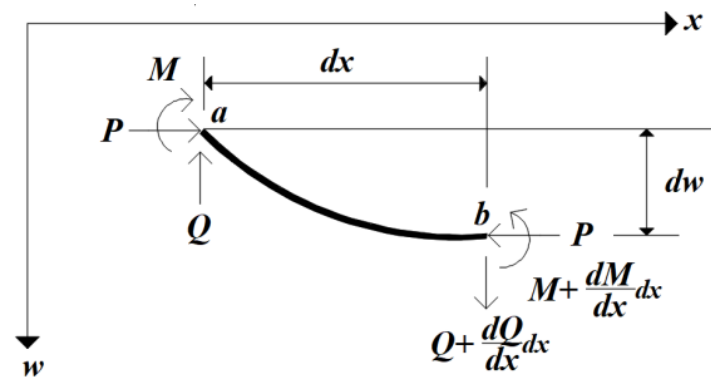

Şekil 1. Eksenel P kuvveti altındaki kolonun serbest cisim diyagramı

$$
M^{\prime}=Q+P w^{\prime}
$$

Düşey ve yatay kuvvetlerin dengesinden, normal ve kesme kuvvetlerindeki değişimler Denklem (8)'de verilmiştir.

$$
Q^{\prime}=0, N^{\prime}=0
$$

Yukarıda verilen denklemler kullanılarak, burkulma davranışını idare eden diferansiyel denklemler, kanonik formda aşağıdaki gibi bu çalışmada elde edilmiştir.

$$
\begin{gathered}
\frac{d u}{d x}=\frac{N}{E A(x)} \\
\frac{d w}{d x}=-\left(\frac{k_{s} G A(x)}{k_{s} G A(x)-P}\right) \theta \\
\frac{d \theta}{d x}=\frac{M}{E I(x)} \\
\frac{d N}{d x}=0 \\
\frac{d Q}{d x}=0 \\
\frac{d M}{d x}=Q-P\left(\frac{k_{s} G A(x)}{k_{s} G A(x)-P}\right) \theta
\end{gathered}
$$



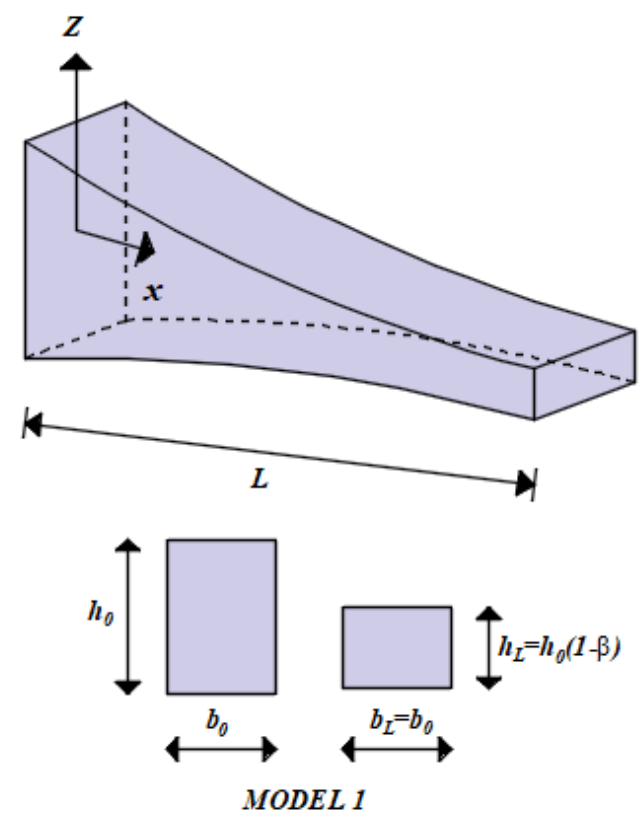
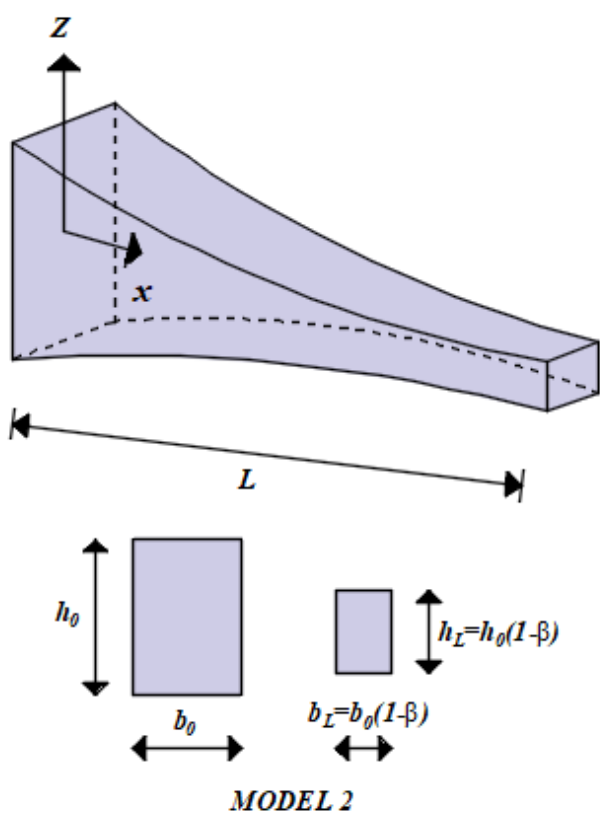

Şekil 2. Ekseni boyunca değişken kesitli kolon modelleri

Denklem (9-14)'de verilen adi diferansiyel denklem takımı, TFY [13-16] ile çözülecektir. TFY, lineer sınır değer problemini başlangıç değer problemine dönüştüren bir çözüm yöntemidir. Başlangıç değer problemi çözümleri beşinci mertebeden Runge-Kutta (RK5) algoritması ile yapılacaktır [17].

$$
F(y)=k_{n} y^{(n)}+k_{n-1} y^{(n-1)}+\ldots+k_{1} y^{\prime}+k_{0}
$$

Denklem (15)'de verilen n. mertebeden diferansiyel denklem, $\mathrm{n}$ adet adi diferansiyel denklem takımına indirgenir. Bu denklem takımı, $\mathrm{n}$ adet homojen ve bir adet homojen olmayan başlangıç değer problemi olarak çözülür. İntegrasyon sabitleri ise problemin sınır koşullarından elde edilir. Bu çalışmada ele alınan problemlerin çözümlerinde Tablo 1'de verilen üç farklı sınır koşulu kullanılmıştır.

Tablo 1. Sınır koşulları

\begin{tabular}{llll}
\hline Ankastre Mesnet (A) & $u=0$ & $w=0$ & $\theta=0$ \\
Sabit Mesnet (S) & $u=0$ & $w=0$ & $M=0$ \\
Serbest Uç (Se) & $u=0$ & $Q=0$ & $M=0$ \\
\hline
\end{tabular}

Analizi yapılan problemin $P$ burkulma yükleri, sınır koşulları dikkate alınarak, diferansiyel denklem takımının homojen çözümünden elde edilen katsayilar matrisinin determinantını sıfır yapan değerlerden elde edilmektedir. Burkulma yükleri, Secant metoduyla iteratif olarak bulunmaktadır.

Ekseni boyunca değişken kesit özelliklerine sahip iki ayrı kolon modeli Şekil 2'de gösterilmiştir. Model 1'de eksen boyunca sadece yükseklik değişirken, Model 2'de hem yükseklik hem de genişlik birlikte değişmektedir. Her iki model için kesit alanı $A(x)$ ve kesit atalet momenti $I(x)$ değişimi Tablo 2'de verilmektedir.
Tablo 2. Kesit alanı ve atalet momenti değiş̧imi

\begin{tabular}{ccc}
\hline Model No & $I(x)$ & $A(x)$ \\
\hline Model 1 & $I_{0}\left(1-\beta \frac{x}{L}\right)^{3}$ & $A_{0}\left(1-\beta \frac{x}{L}\right)$ \\
Model 2 & $I_{0}\left(1-\beta \frac{x}{L}\right)^{4}$ & $A_{0}\left(1-\beta \frac{x}{L}\right)^{2}$ \\
\hline
\end{tabular}

\section{Sayısal Uygulamalar}

\subsection{Uygulama 1}

Kullanılan çözüm yönteminin uygunluğu, yakınsaması ve etkinliğini göstermek için literatürde analitik çözümü verilen homojen-izotrop malzemeye sahip bir kolon ele alınmıştır. Kolonun burkulma analizlerinde kullanılan boyutsuzlaştırma parametreleri Denklem (16)'da verilmiştir.

$$
r=\frac{I_{0}}{A_{0} L^{2}} \quad \overline{P_{c r}}=\frac{P_{c r} L^{2}}{E I_{0}}
$$

Analizlerde, $r=0.01, L=1 \mathrm{~m}, k_{s}=5 / 6$ ve $v=0.3$ olarak alınmıştır. $x=0$ başlangıç noktasında kesit atalet momenti ve alanı sirasiyla $I_{0}=b_{0} h_{0}{ }^{3} / 12$ ve $A_{0}=b_{0} h_{0}$ bağıntılarından hesaplanmıştır.

Model 1 ve Model 2 için çeşitli $\beta$ değerlerine göre kolon boyunca atalet momentinin değişimi Şekil 3'de gösterilmiştir. Tablo 2'de verilen değişim fonksiyonlarında $\beta=0$ alınırsa, problem sabit kesitli kolon problemine dönüşmektedir. Bu durumunda homojen-izotrop malzemeli Timoshenko kolonun çeşitli adım aralıkları ve Sabit-Sabit (S-S), Ankastre-Sabit (A-S), Ankastre-Ankaste (A-A) ve Ankastre-Serbest (A-Se) sınır koşulları için bulunan boyutsuz burkulma yükleri, Tablo 3'de literatürde verilen analitik sonuçlar [18] ile karşılaştırılmıştır. 

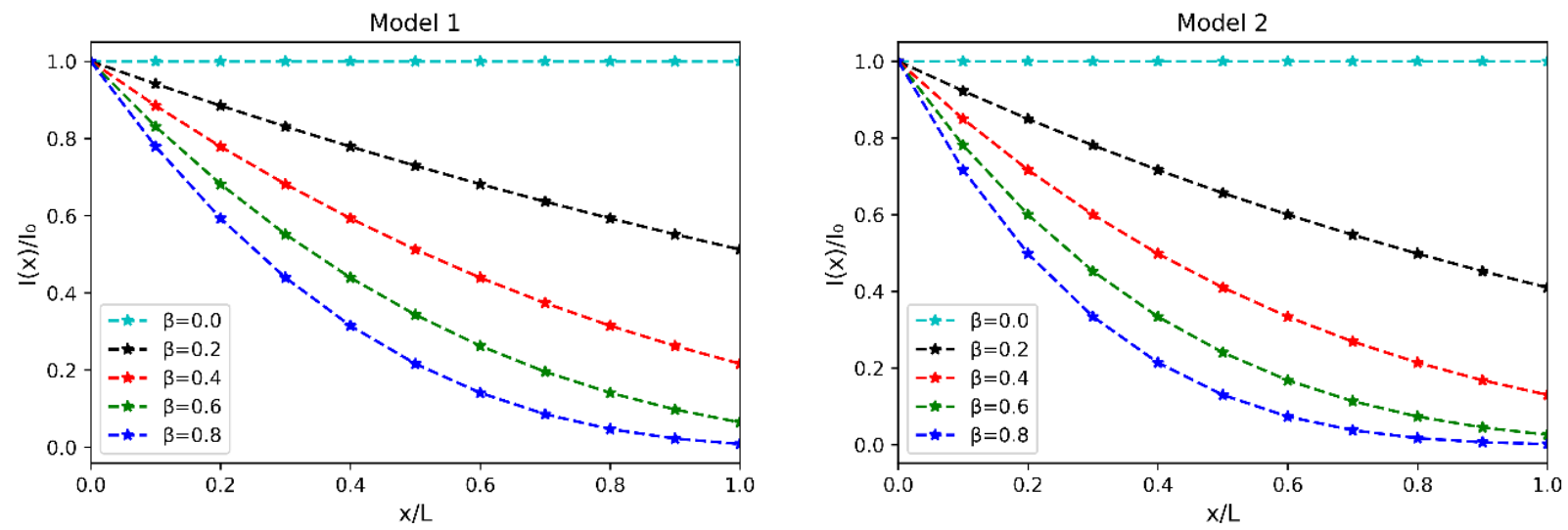

Şekil 3. Çeşitli $\beta$ değerleri için kolon boyunca atalet momentinin değişimi

Tablo 3. Homojen-izotrop Timoshenko kolonların boyutsuz burkulma yükleri

\begin{tabular}{ccccc}
\hline $\begin{array}{c}\text { Sinır } \\
\text { Koşulları }\end{array}$ & $N=5$ & $N=10$ & $N=20$ & Wang \\
\hline S-S & 7.546 & 7.546 & 7.546 & 7.546 \\
A-S & 12.385 & 12.387 & 12.387 & 12.387 \\
A-A & 17.676 & 17.689 & 17.690 & 17.690 \\
A-Se & 2.291 & 2.291 & 2.291 & 2.291 \\
\hline
\end{tabular}

Tablo 3 incelendiğinde, $N=10$ adım aralığında sabit kesitli kolonlarda yeterli derecede yakınsamanın sağlandığ görülmektedir.

Değişken kesitli Timoshenko kolonunun farklı koniklik değerleri ve A-Se sınır koşulu için bulunan boyutsuz burkulma yükleri Tablo 4'de verilmiştir. Tablo 4 incelendiğinde, A-Se sınır koşuluna sahip değişken kesitli Timoshenko kolonları için TFY ile bulunan boyutsuz burkulma yüklerinin, literatürde verilen sonuçlarla oldukça uyumlu olduğu görülmektedir.

Tablo 4. A-Se kolonun farklı koniklik değerleri için boyutsuz burkulma yükleri

\begin{tabular}{ccccc}
\hline & \multicolumn{2}{c}{ Model 1 } & Model 2 \\
$\beta$ & Bu Çalışma & Soltani & Bu Çalışma & Soltani \\
& $N=10$ & {$[11]$} & $N=10$ & {$[11]$} \\
\hline 0.1 & 2.089 & 2.088 & 2.016 & 2.016 \\
0.2 & 1.884 & 1.884 & 1.742 & 1.742 \\
0.3 & 1.676 & 1.676 & 1.471 & 1.471 \\
0.4 & 1.465 & 1.465 & 1.203 & 1.203 \\
0.5 & 1.250 & 1.250 & 0.941 & 0.941 \\
0.6 & 1.029 & 1.029 & 0.688 & 0.688 \\
0.7 & 0.800 & 0.800 & 0.448 & 0.447 \\
0.8 & 0.561 & 0.560 & 0.234 & 0.236 \\
0.9 & 0.301 & 0.301 & 0.069 & 0.073 \\
\hline
\end{tabular}

İki kesit değişim modeli için bulunan boyutsuz burkulma yükleri arasındaki farkın, $\beta$ değeri ile birlikte artmakta olduğu, ayrıca Model 1 kesit değişimi için daha büyük boyutsuz burkulma yüklerinin elde edildiği anlaşılmaktadır.

\subsection{Uygulama 2}

$\mathrm{Bu}$ problemde ilk olarak, uzunluk/kalınlık oranının değişken kesitli kolonların burkulma yüküne etkisi TFY ve Abaqus [19] sonlu elemanlar programı ile araştırılmıştır. Analizlerde kullanılan boyutsuzlaştırma parametresi Denklem (17)'de verilmiş ve $L=1 \mathrm{~m}, v=0.3$ ve $k_{s}=0.85$ alınmıştır.

$$
\overline{P_{c r}}=\frac{P_{c r} L^{2}}{E I_{0}}
$$

Uzunluk/kalınlık oranı $L / h_{0}=5$ olan değişken kesitli Timoshenko kolonlarının burkulma analizlerinin, sonlu eleman (SE) çözümleri iki boyutlu düzlemde yapılmıştır. Kesit değișiminini modelleyebilmek için kolon uzunluğu doğrultusunda 50,100 ve 200 homojen-izotrop elemana bölünmüştür. SE analizlerinde kayma deformasyonlarının dikkate alındığ B21 elemanı kullanılmıştır. Birbiri ardına gelen her iki eleman arasına kiriş tipi bağlantı tanımlanmıştır. Modelin SE programı arayüzündeki görüntüsü Şekil 4'de gösterilmiştir. TFY ile çözümlerde $N=\{5,10,20,50\}$ integrasyon adım aralıkları kullanılarak, çeşitli koniklik oranları ve sınır koşulları için bulunan boyutsuz burkulma yükleri, Tablo 5'de Abaqus programından elde edilen değerler ile karşılaştırılmıştır.

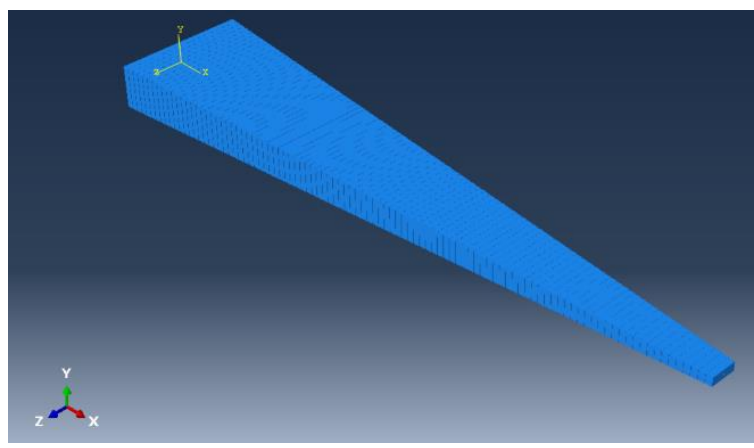

Şekil 4. Değişken kesitli kolunun SE modeli 
Tablo 5. $L / h_{0}=5$ oranı için kolonunun farklı koniklik değerleri için boyutsuz burkulma yükleri

\begin{tabular}{|c|c|c|c|c|c|c|c|c|c|c|}
\hline & & & \multicolumn{2}{|c|}{ A-A } & \multicolumn{2}{|c|}{ A-S } & \multicolumn{2}{|c|}{ S-S } & \multicolumn{2}{|c|}{ A-Se } \\
\hline & & & Model 1 & Model 2 & Model 1 & Model 2 & Model 1 & Model 2 & Model 1 & Model 2 \\
\hline \multirow{7}{*}{$\beta=0.2$} & \multirow{3}{*}{ Abaqus } & 50 Eleman & 21.3893 & 19.0245 & 12.2303 & 10.8761 & 6.5561 & 5.8328 & 1.9755 & 1.8348 \\
\hline & & 100 Eleman & 21.3889 & 19.0241 & 12.2306 & 10.8765 & 6.5565 & 5.8328 & 1.9755 & 1.8348 \\
\hline & & 200 Eleman & 21.3881 & 19.0234 & 12.1481 & 10.8000 & 6.5558 & 5.8324 & 1.9756 & 1.8349 \\
\hline & \multirow{4}{*}{ TFY } & $\mathrm{N}=5$ & 21.3573 & 18.9863 & 12.3941 & 11.0003 & 6.5560 & 5.8326 & 1.9756 & 1.8349 \\
\hline & & $\mathrm{N}=10$ & 21.3836 & 19.0106 & 12.3969 & 11.0027 & 6.5562 & 5.8327 & 1.9756 & 1.8349 \\
\hline & & $\mathrm{N}=20$ & 21.3843 & 19.0112 & 12.3969 & 11.0028 & 6.5562 & 5.8327 & 1.9756 & 1.8349 \\
\hline & & $\mathrm{N}=50$ & 21.3843 & 19.0112 & 12.3969 & 11.0028 & 6.5562 & 5.8327 & 1.9756 & 1.8349 \\
\hline \multirow{7}{*}{$\beta=0.4$} & \multirow{3}{*}{ Abaqus } & 50 Eleman & 14.8838 & 11.2335 & 8.3220 & 6.2828 & 4.4010 & 3.3201 & 1.5335 & 1.2727 \\
\hline & & 100 Eleman & 14.8830 & 11.2328 & 8.3228 & 6.2831 & 4.4014 & 3.3203 & 1.5336 & 1.2728 \\
\hline & & 200 Eleman & 14.8811 & 11.2309 & 8.2523 & 6.2239 & 4.4010 & 3.3200 & 1.5336 & 1.2728 \\
\hline & \multirow{4}{*}{ TFY } & $\mathrm{N}=5$ & 14.8466 & 11.1802 & 8.4065 & 6.3216 & 4.4013 & 3.3204 & 1.5336 & 1.2728 \\
\hline & & $\mathrm{N}=10$ & 14.8722 & 11.2016 & 8.4084 & 6.3229 & 4.4012 & 3.3203 & 1.5336 & 1.2728 \\
\hline & & $\mathrm{N}=20$ & 14.8729 & 11.2025 & 8.4084 & 6.3229 & 4.4012 & 3.3203 & 1.5336 & 1.2728 \\
\hline & & $\mathrm{N}=50$ & 14.8729 & 11.2025 & 8.4084 & 6.3229 & 4.4012 & 3.3203 & 1.5336 & 1.2728 \\
\hline \multirow{7}{*}{$\beta=0.6$} & \multirow{3}{*}{ Abaqus } & 50 Eleman & 8.8620 & 5.2103 & 4.8514 & 2.8530 & 2.5452 & 1.4865 & 1.0747 & 0.7325 \\
\hline & & 100 Eleman & 8.8601 & 5.2084 & 4.8525 & 2.8537 & 2.5456 & 1.4869 & 1.0748 & 0.7327 \\
\hline & & 200 Eleman & 8.8568 & 5.2046 & 4.7955 & 2.8124 & 2.5453 & 1.4867 & 1.0749 & 0.7327 \\
\hline & \multirow{4}{*}{ TFY } & $\mathrm{N}=5$ & 8.8250 & 5.1953 & 4.8852 & 2.8561 & 2.5459 & 1.4873 & 1.0749 & 0.7328 \\
\hline & & $\mathrm{N}=10$ & 8.8453 & 5.1728 & 4.8857 & 2.8564 & 2.5456 & 1.4870 & 1.0749 & 0.7327 \\
\hline & & $\mathrm{N}=20$ & 8.8469 & 5.1755 & 4.8857 & 2.8564 & 2.5456 & 1.4869 & 1.0749 & 0.7327 \\
\hline & & $\mathrm{N}=50$ & 8.8469 & 5.1755 & 4.8857 & 2.8563 & 2.5456 & 1.4869 & 1.0749 & 0.7327 \\
\hline \multirow{7}{*}{$\beta=0.8$} & \multirow{3}{*}{ Abaqus } & 50 Eleman & 3.6635 & 1.3539 & 1.9686 & 0.7244 & 1.0435 & 0.3723 & 0.5841 & 0.2535 \\
\hline & & 100 Eleman & 3.6591 & 1.3509 & 1.9701 & 0.7253 & 1.0442 & 0.3728 & 0.5844 & 0.2538 \\
\hline & & 200 Eleman & 3.6498 & 1.3421 & 1.9302 & 0.7040 & 1.0442 & 0.3728 & 0.5845 & 0.2539 \\
\hline & \multirow{4}{*}{ TFY } & $\mathrm{N}=5$ & 3.7632 & 1.0304 & 1.9645 & 0.6897 & 1.0434 & 0.3698 & 0.5844 & 0.2531 \\
\hline & & $\mathrm{N}=10$ & 3.6416 & 1.3301 & 1.9769 & 0.7219 & 1.0445 & 0.3730 & 0.5845 & 0.2539 \\
\hline & & $\mathrm{N}=20$ & 3.6482 & 1.3335 & 1.9767 & 0.7221 & 1.0444 & 0.3730 & 0.5845 & 0.2539 \\
\hline & & $\mathrm{N}=50$ & 3.6483 & 1.3340 & 1.9767 & 0.7221 & 1.0444 & 0.3729 & 0.5845 & 0.2539 \\
\hline
\end{tabular}

Tablo 5 incelendiğinde, A-A sınır koşuluna sahip kolonların Abaqus sonlu elemanlar programından 50 ve 200 eleman kullanilarak elde edilen boyutsuz burkulma yüklerinin bağıl farkları sırasıyla, $\beta=0.2$ ve $\{$ Model 1 ve Model 2$\}$ için $\left\{\% 5.61 \times 10^{-3}, \% 5.78 \times 10^{-3}\right\}$ iken, $\beta=0.8$ ve \{Model 1 ve Model 2$\}$ için $\{\% 0.375, \% 0.879$ \}olarak elde edilmiştir.

Aynı sınır koşuluna sahip Timoshenko kolonlarının TFY ile $N=\{10,50\}$ adım aralıkları için bulunan boyutsuz burkulma yüklerinin bağıl farkları sırasıyla, $\beta=0.2$ ve $\{$ Model 1 ve Model 2$\}$ için $\left\{\% 3.27 \times 10^{-3}, \% 3.16 \times 10^{-3}\right\}$ iken, $\beta=0.8$ ve $\{$ Model 1 ve Model 2$\}$ için $\{\% 0.184, \% 0.292\}$ olarak bulunmaktadır. Farklı $L / h_{0}$ oranları için değişken kesitli Timoshenko kolonlarının iki ayrı kesit değişim modeli ve çeşitli koniklik oranlarındaki boyutsuz burkulma yükleri Tablo 6-7'de verilmiştir. Analizlerde $N=20$ adım aralığ kullanılmıştır. 
Tablo 6. $L / h_{0}=10$ oranı için kolonunun farklı koniklik değerleri için boyutsuz burkulma yükleri

\begin{tabular}{ccccccccc}
\hline & \multicolumn{2}{c}{ A-A } & \multicolumn{2}{c}{ A-S } & \multicolumn{2}{c}{ S-S } & \multicolumn{2}{c}{ A-Se } \\
$\beta$ & Model 1 & Model 2 & Model 1 & Model 2 & Model 1 & Model 2 & Model 1 & Model 2 \\
\hline 0.2 & 26.2033 & 23.3500 & 13.9063 & 12.3828 & 6.9492 & 6.1883 & 2.0111 & 1.8711 \\
0.4 & 17.5229 & 13.3253 & 9.2323 & 7.0080 & 4.6109 & 3.4920 & 1.5600 & 1.3000 \\
0.6 & 10.0194 & 5.9926 & 5.2537 & 3.1291 & 2.6389 & 1.5552 & 1.0925 & 0.7505 \\
0.8 & 3.9674 & 1.5114 & 2.0817 & 0.7848 & 1.0725 & 0.3891 & 0.5937 & 0.2616 \\
\hline
\end{tabular}

Tablo 7. $L / h_{0}=20$ oranı için kolonunun farklı koniklik değerleri için boyutsuz burkulma yükleri

\begin{tabular}{cccccccccc}
\hline & \multicolumn{2}{c}{ A-A } & \multicolumn{2}{c}{ A-S } & \multicolumn{2}{c}{ S-S } & \multicolumn{2}{c}{ A-Se } \\
$\beta$ & Model 1 & Model 2 & Model 1 & Model 2 & Model 1 & Model 2 & Model 1 & Model 2 \\
\hline 0.2 & 27.7665 & 24.7585 & 14.3427 & 12.7829 & 7.0549 & 6.2840 & 2.0202 & 1.8804 \\
0.4 & 18.3374 & 13.9801 & 9.4637 & 7.2018 & 4.6664 & 3.5376 & 1.5668 & 1.3070 \\
0.6 & 10.3605 & 6.2327 & 5.3541 & 3.2047 & 2.6633 & 1.5731 & 1.0970 & 0.7551 \\
0.8 & 4.0551 & 1.5614 & 2.1095 & 0.8019 & 1.0798 & 0.3934 & 0.5961 & 0.2636 \\
\hline
\end{tabular}

Tablo 6-7 incelendiğinde $L / h_{0}$ oranı arttıkça dört farklı sınır koşulu için de boyutsuz burkulma yüklerinin arttı̆̆ 1 görülmüştür. En büyük boyutsuz burkulma yükleri A-A sinır koşuluna sahip kolonlarda elde edilirken, en küçük boyutsuz burkulma yükleri ise, A-Se sınır koşulu için elde edilmiștir.

İki farklı sınır koşulu için Model 1 kesit değişimine sahip Timoshenko kolonlarının, koniklik oranı ve uzunluk/kalınlık oranına bağlı boyutsuz burkulma yüklerinin eşdeğer eğrileri Şekil 5-6'da verilmiştir.

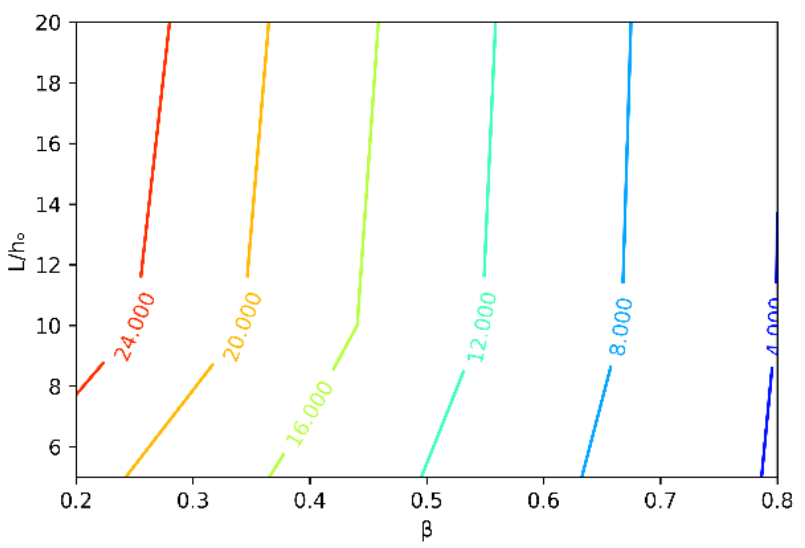

Şekil 5. A-A sınır koşulu için kolunun boyutsuz burkulma yüklerinin eşdeğer eğrileri

Şekil 5 incelendiğinde, A-A sınır koşuluna sahip kolonlarda, düşük $\beta$ değerleri için $L / h_{0}$ oranının boyutsuz burkulma yüküne etkisinin, yüksek $\beta$ değerlerine kıyasla daha fazla olduğı görülmektedir.

Şekil 6'ya göre ise, A-Se sınır koşulu altında kolonda çeşitli $\quad \beta$ değerleri için elde edilen boyutsuz burkulma yüklerinin $L / h_{0}$ oranlarından çok az etkilendiği anlaşılmaktadır.

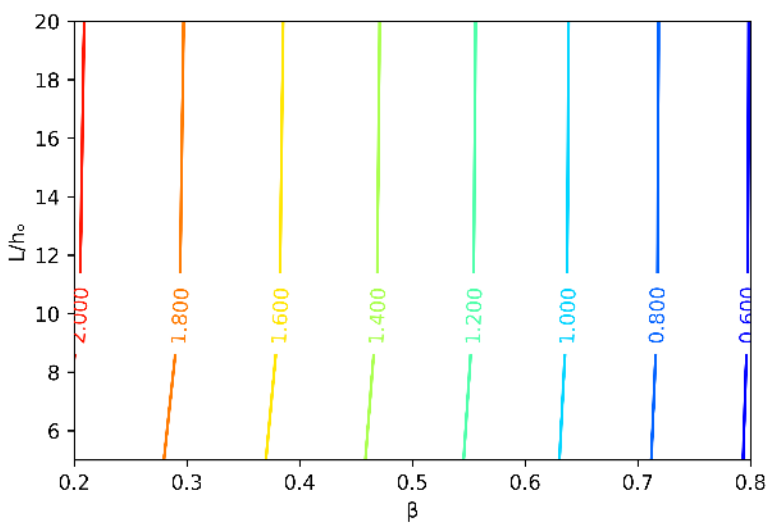

Şekil 6. A-Se sınır koşulu için kolunun boyutsuz burkulma yüklerinin eşdeğer eğrileri

\section{Sonuçlar}

$\mathrm{Bu}$ çalışmada değişken kesitli, Timoshenko kiriş teorisine dayalı kolonların burkulma analizi TFY kullanılarak yapılmıştır. Araştırmada iki farklı kesit değişim modeli kullanılmıştır. Analizlerde, $\beta$ değeri arttıkça, elde edilen boyutsuz burkulma yükleri azalmaktadır. Dolayısıyla, çözüm yöntemlerinde kullanılan eleman sayısı ve adım aralıklarının önemi artmaktadır. $L / h_{0}$ oranı azaldıkça kayma deformasyonlarının boyutsuz burkulma yüküne etkisinin artmakta olduğu görülmektedir. Ayrıca, değişken kesitli kolonlarda $L / h_{0}$ oranının, burkulma yükü üzerindeki etkisinin, sınır koşullarına bağlı olarak değiştiği anlaşılmaktadır. Yapılan çalışma sonucunda, TFY'nin değişken kesitli kolonların burkulma analizinde etkin bir şekilde kullanılabildiği gösterilmiştir.

\section{Çıkar çatışması}

Yazarlar çıkar çatışması olmadığını beyan etmektedir.

Benzerlik oranı (iThenticate): $\% 10$ 


\section{Kaynaklar}

[1] Q. S. Li, Exact solutions for buckling of non-uniform columns under axial concentrated and distributed loading. European Journal of Mechanics-A/Solids, 20 (3), 485-500, 2001. https://doi.org/10.1016/S09977538(01)01143-3.

[2] I. Elishakoff, Inverse buckling problem for inhomogeneous columns. International Journal of Solids and Structures, 38 (3), 457-464, 2001. https://doi.org/10.1016/S0020-7683(00)00049-4.

[3] J. K. Lee and B. K. Lee, Free vibration and buckling of tapered columns made of axially functionally graded materials. Applied Mathematical Modelling, 75, 73-87, 2019. https://doi.org/10.1016/j.apm.2019.05.010 .

[4] S. B. Coşkun and M. T. Atay, Determination of critical buckling load for elastic columns of constant and variable cross-sections using variational iteration method. Computers \& Mathematics with Applications,58 (11-12), 2260-2266, 2009. https://doi.org/10.1016/j.camwa.2009.03.072 .

[5] A. Shahba, R. Attarnejad, and S. Hajilar, Free vibration and stability of axially functionally graded tapered Euler-Bernoulli beams. Shock and Vibration,18 (5), 683-696, 2011. https://doi.org/10.3233/SAV-20100589.

[6] G. Binnur ve S. Erim, Değişsken kesitli ankastre tımoshenko kirişin statik stabilite analizi. Dokuz Eylül Üniversitesi Mühendislik Fakültesi Fen ve Mühendislik Dergisi,2(2), 75-86, 2000.

[7] Y. Huang and X. F. Li, Buckling analysis of nonuniform and axially graded columns with varying flexural rigidity. Journal of engineering mechanics,137(1), 73-81, 2011. https://doi.org/ 10.1061/(ASCE)EM.1943-7889.0000206 .

[8] M. Soltani, Finite element modelling for buckling analysis of tapered axially functionally graded Timoshenko beam on elastic foundation. Mechanics of Advanced Composite Structures, 7(2), 203-218, 2020.

[9] S. Rajasekaran, Buckling and vibration of axially functionally graded nonuniform beams using differential transformation based dynamic stiffness approach. Meccanica, 48(5), 1053-1070, 2013. http://dx.doi.org/10.1007/s11012-012-9651-1

[10] A. Shahba, R. Attarnejad, M. T. Marvi and S. Hajilar, Free vibration and stability analysis of axially functionally graded tapered Timoshenko beams with classical and non-classical boundary conditions. Composites Part B: Engineering, 42(4), 801-808, 2011. https://doi.org/10.1016/j.compositesb.2011.01.017.

[11] M. Soltani and B. Asgarian, Finite element formulation for linear stability analysis of axially functionally graded nonprismatic timoshenko beam. International Journal of Structural Stability and dynamics, 19(02), 1950002, $2019 . \quad$ https://doi.org/10.1142/ S0219455419500020.

[12] B. Akgöz, Ritz yöntemi ile değişken kesitli kolonların burkulma analizi.Mühendislik Bilimleri ve Tasarım Dergisi,7(2), 452-458, 2019. https://doi.org/ 10.21923/jesd.539288.

[13] T. A. Aslan, A. R. Noori ve B. Temel, Fonksiyonel derecelenmiş malzemeli kirişlerin sönümlü ve sönümsüz zorlanmış titreşim analizi. Çukurova Üniversitesi Mühendislik-Mimarlık Fakültesi Dergisi, 35(2), 497-510, 2020. https://doi.org/ 10.21605/cukurovaummfd.792455.

[14] T. A. Aslan, A. R. Noori ve B. Temel, Daire eksenli yapı elemanlarının tamamlayıcı fonksiyonlar yöntemi ile statik analizi. Çukurova Üniversitesi MühendislikMimarlık Fakültesi Dergisi,32(1), 23-30, 2017. https://doi.org/10.21605/cukurovaummfd.310041.

[15] A. R. Noori, T. A. Aslan and B. Temel, An efficient approach for in-plane free and forced vibrations of axially functionally graded parabolic arches with nonuniform cross section. Composite Structures, 200, 701-710, 2018. https://doi.org/10.1016/j.compstruct. 2018.05.077.

[16] H. Rasooli ve B. Temel, Değişken kesitli ve tabakalanmiş kompozit malzemeli doğru ve daire eksenli karma sistemlerin tamamlayici fonksiyonlar yöntemi ile statik analizi. Niğde Ömer Halisdemir Üniversitesi Mühendislik Bilimleri Dergisi, 8(3), 4656, 2019. https://doi.org/10.28948/ngumuh.627482

[17] S.C. Chapra ve R. P. Canale, Yazılım ve Programlama Uygulamalarıyla Mühendisler İçin Sayısal Yöntemler. Literatür Yayınevi, 2003.

[18] C.M. Wang, C.Y. Wang and J.N.Reddy, Exact Solutions for Buckling of Structural Members. Florida CRC Press, 2005.

[19] Dassault Systèmes, ABAQUS/CAE v6.14, 2016. 